\title{
Analysis of user characteristics related to drop-off detection with long cane
}

\author{
Dae Shik Kim, PhD; ${ }^{1 *}$ Robert Wall Emerson, PhD; ${ }^{1}$ Amy Curtis, PhD $^{2}$ \\ ${ }^{1}$ Department of Blindness and Low Vision Studies and ${ }^{2}$ Department of Interdisciplinary Health Sciences PhD Program, \\ Western Michigan University, Kalamazoo, MI
}

\begin{abstract}
This study examined how user characteristics affect drop-off detection with the long cane. A mixed-measures design with block randomization was used for the study, in which 32 visually impaired adults attempted to detect the drop-offs using different cane techniques. Younger cane users detected dropoffs significantly more reliably $($ mean $+/$ - standard deviation $=$ $74.2 \%+/-11.2 \%$ of the time) than older cane users $(60.9 \%+/-10.8 \%), p=0.009$. The drop-off detection threshold of the younger participants $(5.2+/-2.1 \mathrm{~cm})$ was also statistically significantly smaller than that of the older participants $(7.9+/-2.2 \mathrm{~cm}), p=0.007$. Those with early-onset visual impairment $(78.0 \%+/-9.0 \%)$ also detected drop-offs significantly more reliably than those with later-onset visual impairment $(67.3 \%+/-12.4 \%), p=0.01$. No interaction occurred between examined user characteristics (age and age at onset of visual impairment) and the type of cane technique used in dropoff detection. The findings of the study may help orientation and mobility specialists select appropriate cane techniques in accordance with the cane user's age and onset of visual impairment.
\end{abstract}

Key words: age, blind, cane user, detection threshold, drop-off detection, long cane technique, older adults, onset of visual impairment, orientation and mobility, visually impaired.

\section{INTRODUCTION}

Drop-off detection with the long cane, which appears to involve proprioceptive/kinesthetic and vibrotactile perception [1], is critical for the safe travel of cane users who are blind. Researchers have well documented that aging is associated with deterioration of perceptual sensitivities [2-4]. Many studies have also shown the existence of sensitive (critical) periods for optimal development of percep- tual abilities [5-8]. Given this, the age of travelers who are blind and their age at the onset of visual impairment, as well as different types of cane techniques, may be related to the ability of a traveler who is blind to detect drop-offs with the long cane.

Most travelers who are blind rely on a long cane to detect obstacles and drop-offs on their walking paths [9]. The two-point touch technique-moving the cane from side to side and touching the edges of one's walking path in an arc slightly wider than one's shoulders - has been the standard long cane technique since its development during World War II [9-10]. The constant contact techniquesweeping the cane from side to side in an arc slightly wider than one's shoulders while keeping the cane tip in contact with the surface at all times [11] — has also been widely used by travelers who are blind in the past few decades. Although these two techniques are similar in many aspects, the primary difference is that with the constant contact technique, the cane tip stays in constant contact with the walking surface, including while the cane is swung back and forth, whereas with the two-point touch technique, the cane tip is lifted off the walking surface and swung to the opposite side between each tap on the surface.

\footnotetext{
Abbreviations: O\&M = orientation and mobility, WMU = Western Michigan University.

* Address all correspondence to Dae Shik Kim, PhD; Western Michigan University, Department of Blindness and Low Vision Studies, 1903 W Michigan Avenue, Kalamazoo, MI 49002-5218; 269-387-3447; fax: 269-387-3567.
}

Email: dae.kim@wmich.edu

DOI:10.1682/JRRD.2009.10.0175 
Regardless of which cane technique is used, travelers who are blind must reliably detect surface elevation changes, particularly drop-offs; a cane user may fall or accidentally put him- or herself in the collision path of an oncoming vehicle by missing a curb while walking on a sidewalk [12]. Drop-off detection becomes particularly important as a person ages, since the consequences of falls are often serious among older individuals [13-15]. As many as 75 percent of older individuals who suffer fallinduced hip fractures do not fully recover their ambulatory and activities of daily living functions [16]. Between 32 and 80 percent of older individuals who survive the hospitalization following a fall-induced hip fracture incur permanent disability [17]. In addition, 15 percent of older individuals who fracture their hips die in the hospital, and more than 30 percent of survivors do not live beyond 1 year [18].

Age-related deterioration of perceptual sensitivities appears to be present across different perceptual modalities, including vision [19-20], hearing [21-22], taste [23], and smell [24]. Declines in proprioceptive/kinesthetic [2526] and vibrotactile sensitivities [27-28] of older individuals have also been documented. In addition, aging negatively affects one's balance [29-30] and increases postural sway during walking [31]. Such decline in balance and increase in body sway may augment the variability of motion-related parameters. This may negatively affect one's ability to detect subtle changes in body position while walking with a long cane (e.g., changes in wrist and elbow angles of the cane-holding hand), since maintaining motion-related parameters relatively constant appears to help kinesthetic and vibrotactile perception [32].

We found no published experimental studies that examined the effect of age on drop-off detection. A preliminary study indicated a negative correlation between a participant's age and drop-off detection performance [33], but the study design did not allow us to infer the results to the corresponding population.

Age at onset of sensory loss, including vision loss, also appears to affect perceptual abilities because distinct sensitive (critical) periods that allow full development of perceptual abilities exist [5-8]. These sensitive periods differ across sensory modalities [34-35]. For example, the sensitive period for stereoacuity ends at 36 months [36], while the highly plastic period for the development of central auditory system close out at age 7 [37]. Drever suggested that kinesthetic practice beyond the age of 4 does not significantly improve an individual's kinesthetic abilities [38], while Facchini and Aglioti reported that tactual discrimination of grating orientation significantly improved after
90 minutes of practice by blindfolded sighted adults [39], suggesting effective vibrotactile learning even in adulthood. Given the possibility of varying sensitive periods for kinesthetic/proprioceptive and vibrotactile perceptual learning, comparison of drop-off detection performance between the cane users who have earlier-onset visual impairment and those who have later-onset impairment is important. A preliminary study showed that cane users with earlier-onset visual impairment detected drop-offs better than those with later-onset visual impairment [33]; however, this was within the sample in which 10 of the 15 participants had later-onset impairment. We have not found any other published experimental design studies that investigated how the age at onset of visual impairment affects drop-off detection performance.

Albeit with variation [3], apparently significant ageassociated deterioration of proprioceptive/kinesthetic sensitivities occurs as early as one's 50s [40] and often by the 60s [41-43]. Deterioration of vibrotactile sensitivities with aging appears somewhat less consistent. For example, sensitivities to certain low-frequency vibrotactile stimuli do not deteriorate until one's 70s [44] or even early 80s [45]. If cane users rely more on proprioceptive/ kinesthetic perception to detect drop-offs when using the two-point touch technique and rely more on vibrotactile perception to detect drop-offs when using the constant contact technique, differential deterioration of proprioceptive/kinesthetic and vibrotactile sensitivities may indicate possible interaction between a cane user's age and the type of cane technique used in drop-off detection. In addition, although anecdotal, some orientation and mobility (O\&M) specialists who work with both younger and older consumers have reported that older cane users tend to detect drop-offs far better with the constant contact technique than with the two-point touch technique, while this difference is smaller for younger cane users."

One of the primary purposes of this study was to examine how age affects drop-off detection performance. Another purpose of the study was to investigate how the age at onset of visual impairment affects drop-off detection. In addition, we examined whether the following two specific interactions were present: (1) cane user's age and the type of cane technique used in drop-off detection and (2) age at onset of visual impairment and the type of cane technique used in drop-off detection.

\footnotetext{
*Personal communication, R. LaDuke, EdD, 2009 Feb 2; M. Weessies, MA, 2009 Feb 4.
} 


\section{METHODS}

\section{Study Design and Recruitment Criteria}

This study used a mixed-measures design with block randomization, in which the participants used either the twopoint touch technique or the constant contact technique to detect drop-offs of various depths. Legally blind adults with no other disabilities were eligible to participate. Participant selection criteria also included familiarity with both the twopoint touch and constant contact techniques, as well as a minimum of 1 month of cane training. Although the criterion was not required, we tried to acquire a sample balanced in age, cane-use experience, and preferred cane technique.

A total of 32 individuals participated in the study15 of them participated in 2008 [33], while the remaining 17 participated in 2009. Given the identical recruitment criteria and experimental protocol during both periods, the data from the previous 15 participants were combined with those from the newly recruited 17 for the analyses.

\section{Apparatus}

Six carpeted platforms ( $2.4 \mathrm{~m}$ long, $1.2 \mathrm{~m}$ wide, $20.3 \mathrm{~cm}$ high) were used to form a 9.8 m-long walkway (Figure 1). The walkway was $1.2 \mathrm{~m}$ wide for the first half and $2.4 \mathrm{~m}$ wide for the latter half that led to the drop-off. The drop-off depth was varied by the use of two plywood boards $(0.6 \mathrm{~m}$ long, $1.2 \mathrm{~m}$ wide) that were placed on top of braced rectangular wooden frames ( $0.6 \mathrm{~m}$ long, $1.2 \mathrm{~m}$ wide, $5.1 \mathrm{~cm}$ high). Carpeting on the plywood boards was identical to the carpeting on the walkway, which was intended to prevent the participants from using tactile and auditory feedback for detecting drop-offs. Identical long canes (Ambutech UltraLite Graphite Rigid Cane; Winnipeg, Manitoba, Canada) of different lengths were used for all participants. All canes were equipped with identical cane tips (Ambutech MT4080 High Mileage Tip). The length of the cane used by each participant was determined based on height, following the guideline outlined in LaGrow and Weessies [46]: each participant was given a cane that was as long as the vertical distance from the ground to $2 \mathrm{in}$. above the participant's xiphoid process. All trials were videotaped with a digital camcorder (Panasonic SDR-S10P1; Seacaucus, New Jersey).

\section{Research Procedure}

The Western Michigan University (WMU) College of Health and Human Services building's basement hallway

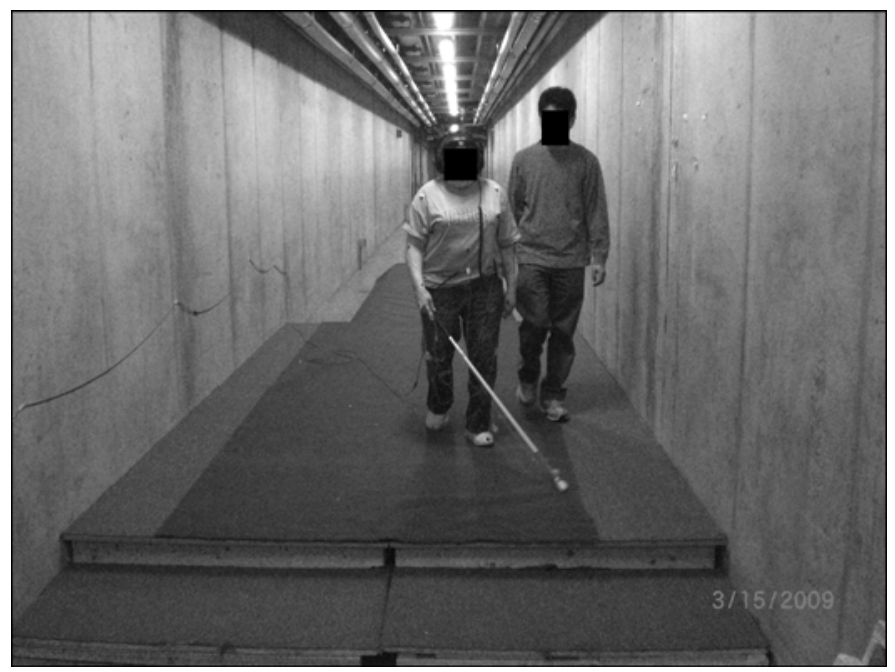

Figure 1.

Participant approaching drop-off on $32 \mathrm{ft}$-long (9.8 m) walkway used in study.

was used for all experiments. Upon arrival at the site, each participant received information on the risks and benefits of participating in the study before signing an informed consent form approved by WMU's Human Subjects Institutional Review Board. Through verbal briefing and two practice trials, participants learned about the test site and experiment procedure. Participants wore sleep-shades and a full-size headphone set (RadioShack Full-Size Stereo Headphone 33-1225; Fort Worth, Texas) connected to an MP3 player (Apple iPod Generation 5; Cupertino, California) during all trials, from which they heard rhythmic beats (90-110 beats per minute) over a white noise background (recorded by Sound for Life, available at http://www.amazon.com/gp/product/B0010S6L3G/ref=dm sp alb). The experimenter (a certified O\&M specialist) set the speed of the rhythmic beats based on the participant's comfortable stepping speed; then the participant was instructed to synchronize his or her steps to the beats during all trials. Such instruction was intended to help the participant walk at a consistent pace throughout the trials, limiting the potential confounding effect of walking speed on drop-off detection.

Each participant was positioned at the center of the walkway, squarely facing the drop-off. Randomly selected starting points (between 4.3 and $9.1 \mathrm{~m}$ ) were used for different trials to prevent participants from predicting the distance to the drop-off. Upon receiving a signal from the experimenter, the participant approached the drop-off using either the two-point touch or the constant contact technique. Participants stopped immediately upon detecting the 
drop-off and verbally indicated the detection of the dropoff. The experimenter followed the participant closely and helped if he or she stumbled off the walkway. The experimenter guided the participant to the next starting point on completion of each trial, using a zigzag pattern to prevent the participant from knowing the distance to the drop-off.

Sixty-four trials were completed for each participant: eight trials for each drop-off depth $(2.5 \mathrm{~cm}, 7.6 \mathrm{~cm}$, $12.7 \mathrm{~cm}$, and $17.8 \mathrm{~cm}$ ) for each cane technique (two-point touch and constant contact). We randomly assigned participants to either the two-point touch technique or the constant contact technique first condition. The height of the plywood boards placed against the walkway was changed from trial to trial based on the block randomization method.

A trial was recorded as a miss if the participant fell off the drop-off or would have fallen off the drop-off had not intervened the experimenter. The experimenter had to intervene at times to prevent injuries, particularly when larger drop-offs were presented. Interrater reliability was 98 percent in a preliminary study [33].

\section{Variables}

Drop-off detection performance (dependent variables) was measured by 50 percent absolute drop-off detection threshold, overall drop-off detection rate, and large dropoff detection rate. We calculated the 50 percent absolute drop-off detection threshold for each technique using the psychometric function described in Gescheider [47]. That is, we fitted a cumulative normal distribution curve to the data points to estimate the drop-off depth that was detected in 50 percent of the trials. We computed the overall dropoff detection rate by dividing the total number of detections by total number of trials. Large drop-off detection rate was calculated in a similar manner, but with $12.7 \mathrm{~cm}$ and $17.8 \mathrm{~cm}$ drop-off detection rates combined.

Independent variables of the study included the cane user's age (between-groups variable with two categories: 50 or younger and older than 50), age at onset of visual impairment (between-groups variable with two categories: 4 or younger and older than 4), and the type of cane technique used in drop-off detection trial (within-group variable with two categories: two-point touch and constant contact). Categories for age at onset of visual impairment were created based on the findings of Drever [38], while those for the cane user's age were determined in accordance with the distribution of drop-off detection threshold. In other words, age 50 was used to divide the cane user's age into two categories, given that its relationship with drop-off detection threshold was nonlinear and performance abruptly dropped at approximately 50 years of age. The effect of the type of cane technique used in drop-off detection was examined only as it interacted with the other two variables, since its main effect had been investigated in a previous study [33].

\section{Analyses}

Upon completing a series of preliminary descriptive statistical procedures, we used a two-way mixed-measures analysis of variance to examine the main effects and interaction effects of independent variables on drop-off detection performance; the three-way interaction was not examined in this study because of its limited interpretability and practical benefits. Simple effects, rather than main effects, have been examined in the presence of significant interaction between the factors.

We specifically tested the two-way interaction between the age of the cane user (between-groups factor) and the type of cane technique used in drop-off detection (withingroup variable), as well as the two-way interaction between the age at onset of visual impairment (between-groups factor) and the type of cane technique used in drop-off detection (within-group variable). The interaction between cane user's age and age at onset of visual impairment was examined purely descriptively with no corresponding hypothesis because of the limited statistical power. We used medians as measures of central tendency when a significant deviation from normal distribution occurred, while we used the Welch procedure [48] to control for the probability of a type I error when the homogeneity of variance assumption was violated.

We used a significance level of 0.05 for all statistical tests (two-tailed) in this study. The statistical power was at least 0.52 for main effect and interaction effect tests when a large effect size $(f=0.4)$ was assumed [49-50]. $\mathrm{G}^{*}$ Power version 3.0.10 was used for statistical power analyses [50], while SPSS Inc. version 16.0 (Chicago, Illinois) was used for all other analyses.

\section{RESULTS}

\section{Participant Demographics}

The participants' (18 males, 14 females) visual acuities ranged from no light perception to 20/200. Causes of vision loss included retinitis pigmentosa $(n=5)$, glaucoma $(n=3)$, retinopathy of prematurity $(n=3)$, diabetic retinopathy $(n=$ $3)$, retinal detachment $(n=2)$, microphthalmia $(n=2)$, and others $(n=14)$. The median age of the earlier-onset visual 
impairment group was 28.5 (range $=20$ to 66), while that of the later-onset visual impairment group was 41 (range $=22$ to 75 ). Years of cane use varied from 1 month to 42 years (median $=9$ years) for the younger cane user group, while it ranged from 1 month to 29 years (median $=7$ years) for the older cane user group. Earlier-onset visual impairment group's cane-use experience spanned from 3 years to 42 years (median $=18$ years), while that of the later onset visual impairment group ranged from 1 month to 36 years (median $=5$ years).

\section{Main Effects}

No statistically significant interaction occurred between cane user's age and the type of the cane technique used in drop-off detection trial (Figure 2), $F_{1,30}=$ $0.001, p=0.896$; therefore, the main effect of the cane user's age was analyzed. The drop-off detection threshold of the younger participants $(5.2 \pm 2.1 \mathrm{~cm})$ was statistically significantly smaller than that of the older participants $(7.9 \pm 2.2 \mathrm{~cm}), F_{1,30}=8.505, p=0.007$ (Table). Similarly, the overall drop-off detection rate of the younger cane users $(74.2 \% \pm 11.2 \%)$ was statistically significantly higher than that of those who were older (60.9\% $\pm 10.8 \%), F_{1,30}=7.771, p=0.009$. In addition, the younger cane users' advantage over the older cane users changed little even when those with little functional vision (light perception or less) were trimmed from the

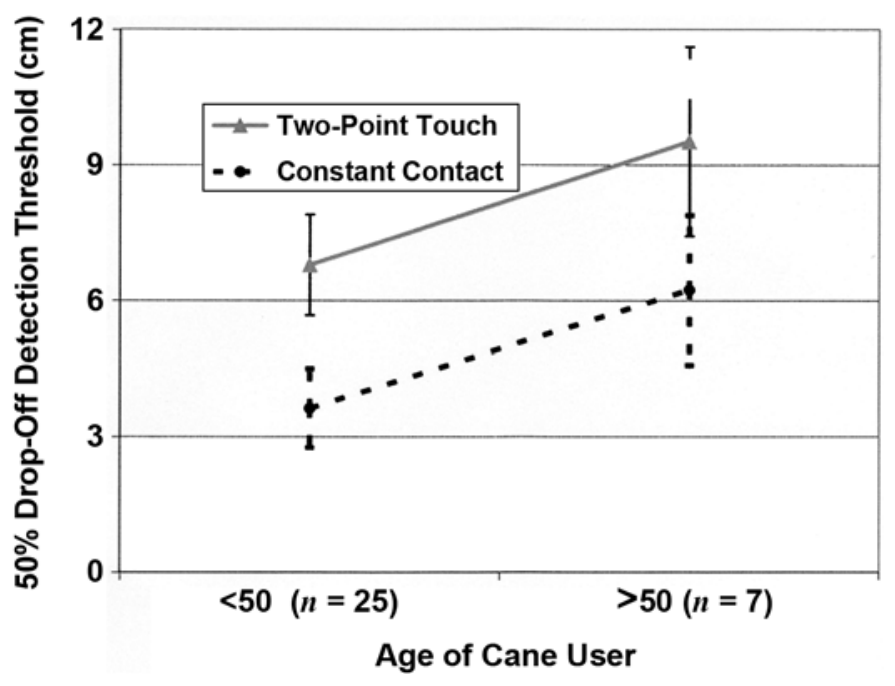

Figure 2.

Effects of cane user's age (between-groups) and type of cane technique used (within-group) on drop-off detection threshold. Error bars indicate $95 \%$ confidence intervals. younger group to equalize the two groups in level of functional vision (younger group $73.3 \% \pm 9.4 \%$, older group $60.9 \% \pm 10.8 \%), F_{1,19}=7.383, p=0.01$.

No statistically significant interaction occurred between age at onset of visual impairment and the type of cane technique used in drop-off detection trial (Figure 3), $F_{1,30}=$ $0.647, p=0.43$. Given this, we examined the main effect of the age at onset of visual impairment. The drop-off detection threshold of the participants who lost their vision at age 4 or younger $(4.5 \pm 1.7 \mathrm{~cm})$ was statistically significantly smaller than that of those with later-onset visual impairment (6.6 \pm $2.4 \mathrm{~cm}$ ), $F_{1,30}=6.307, p=0.02$ (Table). Similarly, the overall drop-off detection rate of the earlier-onset group (78.0\% $\pm 9.0 \%$ ) was statistically significantly higher than that of the later-onset group $(67.3 \% \pm 12.4 \%), F_{1,30}=6.810, p=0.01$. In addition, the drop-off detection rate for large drop-offs $(12.7 \mathrm{~cm}$ and $17.8 \mathrm{~cm})$ was statistically significantly higher for the earlier-onset group $(99.7 \% \pm 0.9 \%)$ than for the lateronset group (94.2\% $\pm 7.7 \%), F_{1,19.9}=9.951, p=0.005$.

\section{Interaction Effects}

As mentioned earlier, for drop-off detection threshold and overall drop-off detection rate, we did not obtain a statistically significant interaction between cane user's age and the type of cane technique used in the drop-off detection trial. However, we found a statistically significant interaction between these two variables for the large drop-off detection rate (Figure 4), $F_{1,30}=7.292, p=0.011$. Simple effects have been in the analyses of these two variables in respect to the large drop-off detection rate [51]. For those who were 50 or younger, large drop-off detection rate with the constant contact technique $(99.3 \% \pm 2.1 \%)$ was statistically significantly higher than that with the two-point touch technique (96.0\% $\pm 7.6 \%), F_{1,24}=5.032, p=0.034$. The constant contact technique's advantage over the twopoint touch technique was larger for older cane users (constant contact $99.1 \% \pm 2.4 \%$, two-point touch $83.9 \% \pm$ $20.0 \%$ ), although this difference was not statistically significant $F_{1,6}=4.983, p=0.067$, perhaps because of the lower statistical power.

The interaction between cane user's age and the age at onset of visual impairment was examined purely descriptively because of the limited statistical power (Figure 5). Added caution is needed when our result is interpreted because only one participant was older and had earlier-onset visual impairment. The drop-off detection performance gap between the earlier- and later-onset visual impairment 
JRRD, Volume 47, Number 3, 2010

Table.

Main effects of cane user's age and age at onset of visual impairment (presented as mean \pm standard deviation) on drop-off detection $(n=32)$.

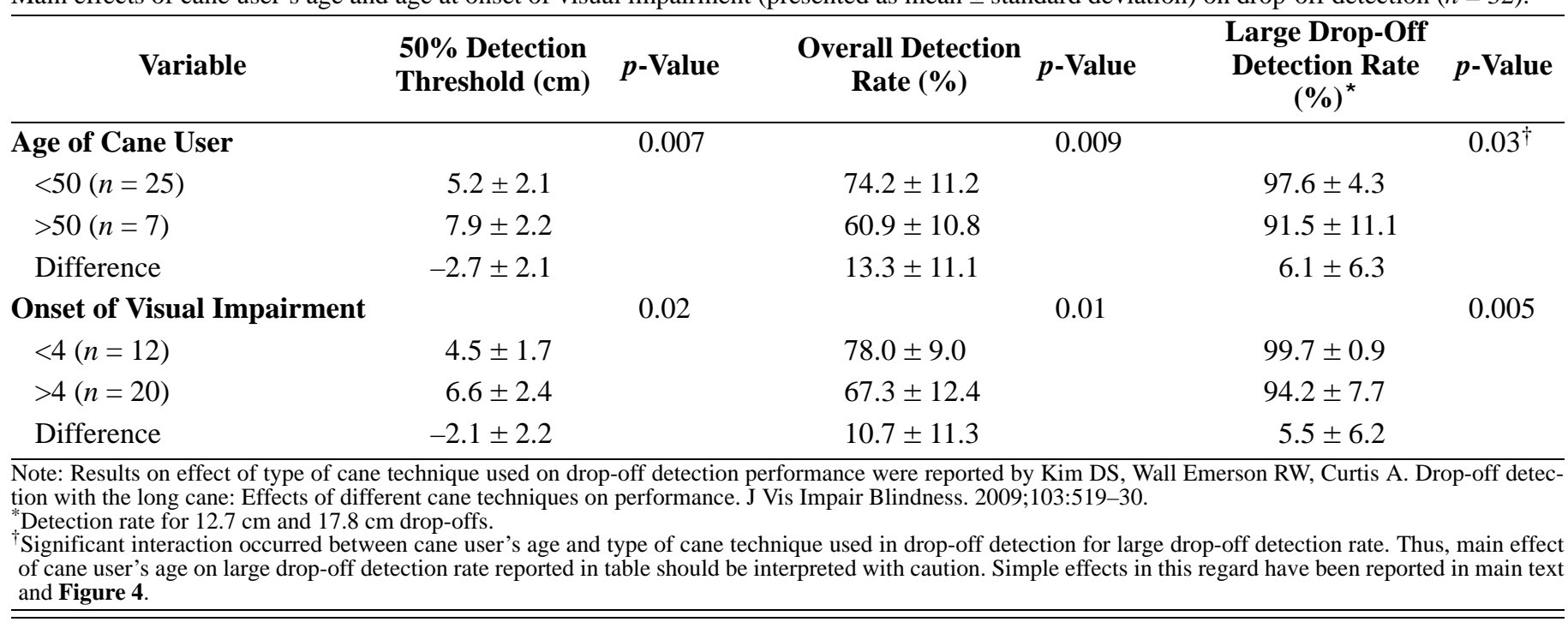

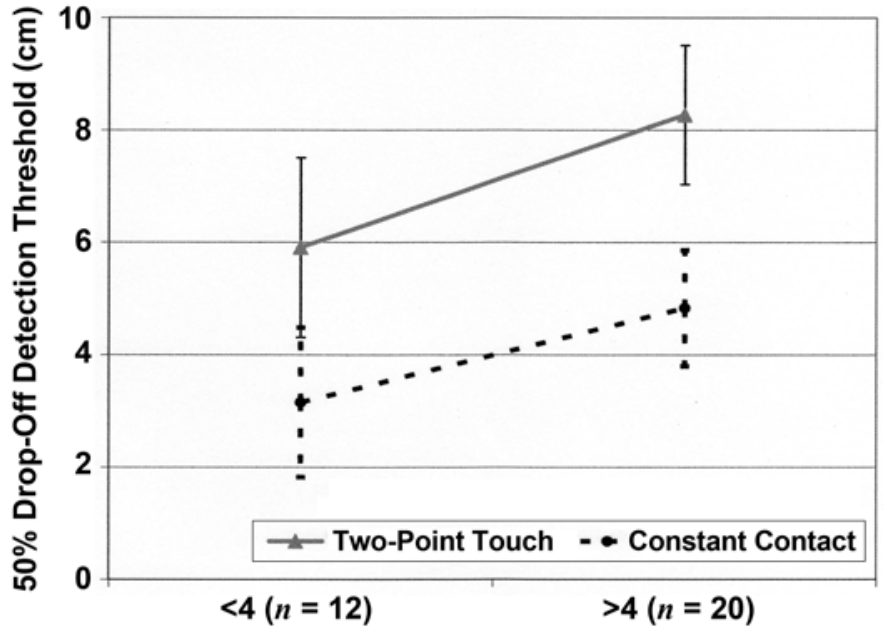

Age at Onset of Visual Impairment

Figure 3.

Effects of age at onset of visual impairment (between-groups) and type of cane technique used (within-group) on drop-off detection threshold. Error bars indicate 95\% confidence intervals.

groups was larger among the older cane users $(3.1 \pm 2.1$ $\mathrm{cm})$ than among the younger ones $(1.3 \pm 2.0 \mathrm{~cm})$.

\section{DISCUSSION}

No interaction occurred between examined user characteristics (age and age at onset of visual impairment) and the

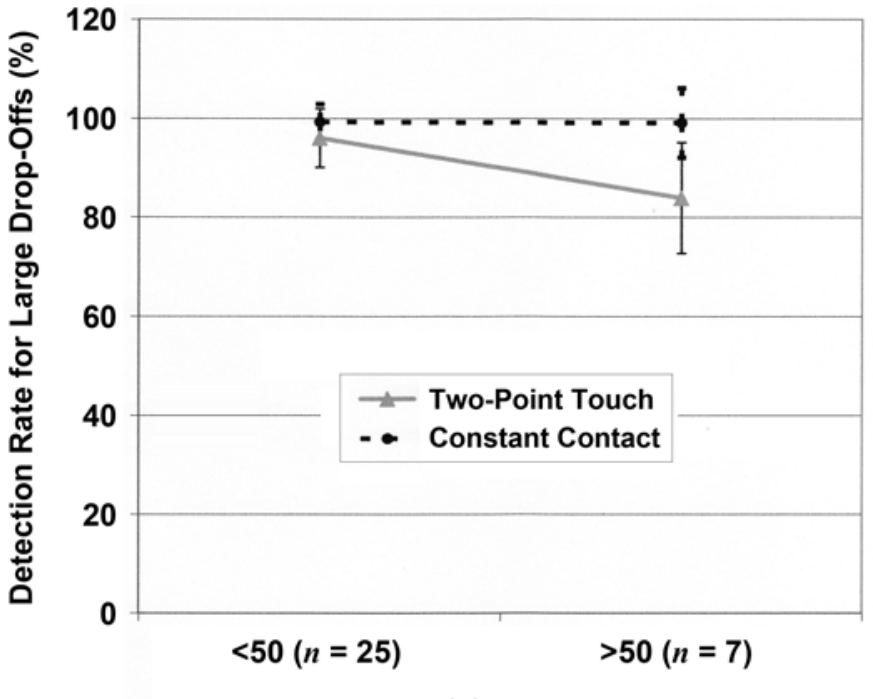

Age of Cane User

Figure 4.

Interaction effect of cane user's age (between-groups) and type of cane technique used in drop-off detection trial (within-group) on large drop-off detection rate. Error bars indicate 95\% confidence intervals.

type of cane technique used in drop-off detection. However, this study found that younger cane users' drop-off detection performance was significantly more reliable than that of the older cane users. This study also found that the drop-off detection performance of cane users with earlier-onset visual impairment was significantly more reliable than those with later-onset visual impairment. 


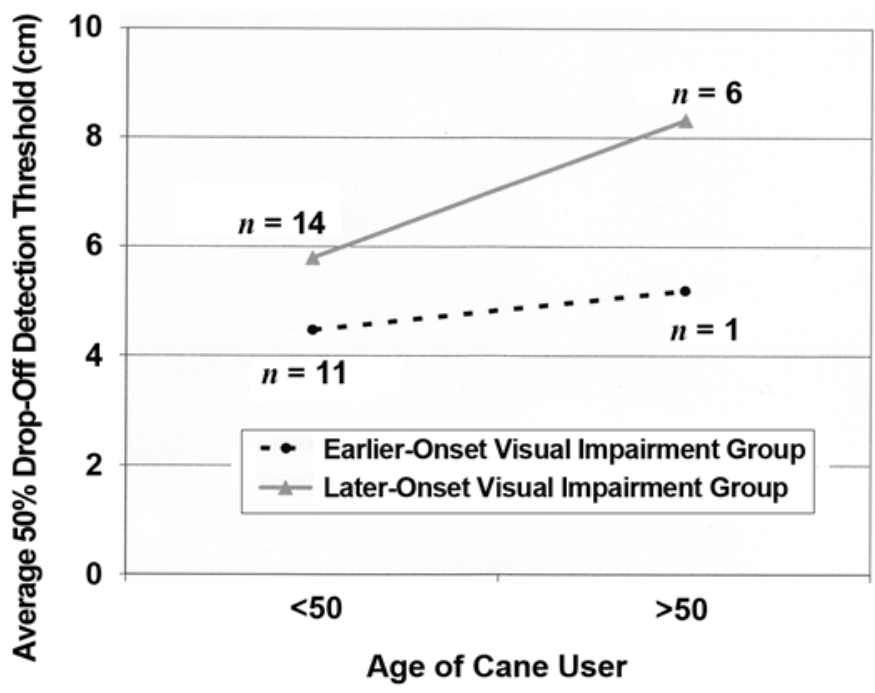

Figure 5.

Interaction between cane user's age and age at onset of visual impairment.

\section{Cane User's Age Effect}

Younger cane users detected drop-offs better than older cane users, which is consistent with the literature on how age is associated with proprioceptive/kinesthetic and vibrotactile perceptual abilities [25-28], as well as the result of a preliminary study result [33]. Decrease in the number of proprioceptors-muscle spindles that encode the limb's position and its rate of change-is to be one of the key underlying biological changes related to age-associated decline in proprioceptive sensitivities [52]. Similarly, reduced density of Pacinian corpuscles with aging is responsible for the decline in vibrotactile sensitivities of older adults [28].

Interestingly, with respect to the smaller drop-off detection rate (1 and 3 inches), the younger cane users' advantage over the older cane user's was rather consistent regardless of which cane technique was used, while such advantage was larger for the two-point touch technique than for the constant contact technique in large drop-off detection. Put another way, the advantage of the constant contact technique over the two-point touch technique was greater for the older cane users than for the younger cane users when the participants tried to detect larger drop-offs, but this advantage was rather consistent across age groups when they attempted to detect smaller drop-offs. Although a mechanism may exist that caused such interaction, we are hesitant to rely on this result for further inference, primarily because of the irregular pattern of this interaction.
In other words, when the detection rate for each drop-off depth was examined separately, a statistically significant interaction occurred between age and the type of cane technique used for $2.5 \mathrm{~cm}$ drop-off detection rate $(p=$ 0.03 ) and $12.7 \mathrm{~cm}$ drop-off detection rate $(p=0.004)$, while such interaction was not statistically significant for the $7.6 \mathrm{~cm}$ drop-off detection rate $(p=0.94)$ and $17.8 \mathrm{~cm}$ drop-off detection rate $(p=0.27)$. The relatively small number of older participants $(n=7)$ in the sample might have contributed to such an inconsistent result.

\section{Age at Onset of Visual Impairment Effect}

Participants with earlier-onset visual impairment detected drop-offs more reliably than those with lateronset visual impairment. One of the possible explanations for such a result may be that although the perceptual sensitivities required for drop-off detection can be learned in adulthood, they can be optimally developed earlier in life, particularly in the absence (or limited amount) of visual input. Given the presence of early-in-life sensitive periods in more thoroughly examined senses (e.g., vision and hearing), we can reasonably suspect the existence of similar sensitive periods for proprioceptive/kinesthetic and vibrotactile senses. However, the literature on this topic is too sparse to support this hypothesis [38-39].

Another possible explanation of age at onset of visual impairment's significant effect on drop-off detection may be found in the age difference between the earlier-onset and later-onset visual impairment groups, with median ages of 28.5 and 41.0, respectively. However, even when the older participants were trimmed from the later-onset visual impairment group to equalize the two groups in respect to age (earlier-onset group mean $=34.0$ years, median $=28.5$, range $=20$ to 66 ; later-onset group mean $=$ 33.7 years, median $=33$, range $=22$ to 47 ), the effect of age at onset of visual impairment was only slightly reduced (earlier-onset group threshold $=4.5 \mathrm{~cm}$, lateronset group threshold $=6.1 \mathrm{~cm}$ ).

Also possible is that the apparent effect of age at onset of visual impairment on drop-off detection resulted from the difference in years of cane use between the two groups. When the participants with shorter cane-use experience were trimmed from the later-onset visual impairment group in an attempt to equalize the two groups in years of cane use (earlier-onset group mean $=19.9$ years, median $=$ 18 , range $=3$ to 42 ; later-onset group mean $=18.5$ years, median $=15.5$ years, range $=10$ to 36 ), the effect of age at onset of visual impairment was reduced more than 
marginally (earlier-onset group threshold $=4.5 \mathrm{~cm}$, lateronset group threshold $=5.6 \mathrm{~cm}$ ), indicating the presence of possible confounding by cane-use experience.

\section{Strengths and Limitations}

We controlled for order effect by randomly assigning participants to either the two-point touch technique first or the constant contact technique first condition. The study design also allowed each participant to serve as his or her own control when the simple effects of the withingroup variable (type of cane technique used in drop-off detection) were examined.

Despite the attempts to acquire a sample that was balanced in important characteristics, such efforts were not entirely successful. Although the years of cane use was similar between the younger and older cane user groups, a substantial difference existed in the years of cane use between the earlier-onset and later-onset visual impairment groups. In addition, only one participant was categorized as an older cane user with earlier-onset visual impairment, which rendered the interpretation of the interaction between cane user's age and age at onset of visual impairment tenuous at best.

\section{Implications and Recommendations}

Considering the increased frequency of falls with aging [13], particularly among the older adults with visual impairment [15], coupled with often serious consequences of falls by those who are older [16], it is critical for O\&M specialists to employ instructional strategies that would minimize the risk of falling by older cane users. While the constant contact technique's advantage over the two-point touch technique in drop-off detection was similar for both younger and older individuals, if a drop-off is missed, older cane users may be more apt to fall than younger ones because of the decline in balance and reaction time [53]. Given this, O\&M specialists may consider recommending the constant contact technique in anticipation of drop-offs or other substantial surface depressions, particularly if the cane user is older or has poor balance. Nevertheless, we do not claim that the constant contact technique is the only technique to be taught and recommended to every long cane user. Instead, cane user's age, physical abilities, and other situations need to be evaluated, along with the merits and limitations of each technique, for appropriate cane technique selection.

Future cane studies may include examination of how biomechanical factors, such as cane arc width and the position of the cane-holding hand, affect drop-off detection performance. Investigation of how ergonomic factors (e.g., cane tips, cane length) affect drop-off detection may also have important practical implications. In addition, we may be able to use analysis techniques that allow us to examine the relationships between the predictor and outcome variables while controlling for the other variables in the model if we obtain a sufficient sample size. Furthermore, to measure overall effectiveness of cane travel, we need to investigate various aspects of long cane performance, including obstacle detection, texture discrimination, and travel efficiency.

\section{CONCLUSIONS}

Younger cane users detected drop-offs significantly more reliably than the older cane users. Cane users with earlier-onset visual impairment also detected drop-offs significantly more reliably than those with later-onset visual impairment. Given that older individuals are more liable to fall than those who are younger, O\&M specialists may consider recommending a cane technique that allows more reliable drop-off detection (e.g., constant contact technique) to the cane users who are older, particularly in anticipation of drop-offs or other considerable surface depressions.

\section{ACKNOWLEDGMENTS}

\section{Author Contributions:}

Study concept and design: D. S. Kim, R. Wall Emerson, A. Curtis. Acquisition of data: D. S. Kim, R. Wall Emerson.

Analysis and interpretation of data: D. S. Kim, R. Wall Emerson, A. Curtis.

Drafting of manuscript: D. S. Kim.

Critical revision of manuscript for important intellectual content:

R. Wall Emerson, A. Curtis.

Statistical analysis: D. S. Kim, A. Curtis.

Obtaining funding: D. S. Kim, R. Wall Emerson.

Administrative, technical, or material support: D. S. Kim, A. Curtis. Study supervision: A. Curtis.

Financial Disclosures: The authors have declared that no competing interests exist.

Funding/Support: This material was based on work supported by grant 2R01 EY12894-07 from the National Eye Institute, National Institutes of Health. Its contents are solely the responsibility of the authors and do not necessarily represent the official views of the National Eye Institute. Institutional Review: This study was approved by the Western Michigan University Human Subjects Institutional Review Board.

Participant Follow-Up: The authors plan to inform participants of the publication of this study. 


\section{REFERENCES}

1. Chan TC, Turvey MT. Perceiving the vertical distances of surfaces by means of a hand-held probe. J Exp Psychol Human Percept Perform. 1991;17(2):347-58.

[PMID: 1830080]

DOI:10.1037/0096-1523.17.2.347

2. Fozard JL, Gordon-Salant S. Changes in vision and hearing with aging. In: Birren JE, Schaie KW, editors. Handbook of the psychology of aging. 5th ed. San Diego (CA): Academic Press; 2001. p. 241-66.

3. Goble DJ, Coxon JP, Wenderoth N, Van Impe A, Swinnen SP. Proprioceptive sensibility in the elderly: Degeneration, functional consequences and plastic-adaptive processes. Neurosci Biobehav Rev. 2009;33(3):271-78. [PMID: 18793668] DOI:10.1016/j.neubiorev.2008.08.012

4. Verrillo R. The effects of aging on the sense of touch. In: Verrillo RT, Zwislocki JJ, editors. Sensory research: Multimodal perspectives. Hillsdale (NJ): L. Erlbaum Associates; 1993. p. 285-98.

5. Blakemore C, Cooper GF. Development of the brain depends on the visual environment. Nature. 1970;228(5270): 477-78. [PMID: 5482506]

DOI:10.1038/228477a0

6. Crair MC, Gillespie DC, Stryker MP. The role of visual experience in the development of columns in cat visual cortex. Science. 1998;279(5350):566-70. [PMID: 9438851]

DOI:10.1126/science.279.5350.566

7. Hirsch HV, Spinelli DN. Visual experience modifies distribution of horizontally and vertically oriented receptive fields in cats. Science. 1970;168(993):869-71. [PMID: 5444065] DOI:10.1126/science.168.3933.869

8. Rauschecker J. Making brain circuits listen. Science. 1999; 285(5434):1686-87. [PMID: 10523187]

DOI:10.1126/science.285.5434.1686

9. Hill E, Ponder P. Orientation and mobility techniques: A guide for the practitioner. New York (NY): American Foundation for the Blind; 1976.

10. Miller M, Hoover R. Foot travel without sight. Outlook Blind. 1946;40:244-51.

11. De Bruin D. The constant contact technique. AAWB Newsletter. 1981;9:23-31.

12. Uslan M, Schriebman K. Drop-off detection in the touch technique. J Vis Impair Blindness. 1980;74(5):179-82.

13. Gillespie LD, Robertson MC, Gillespie WJ, Lamb SE, Gates $\mathrm{S}$, Cumming RG, Rowe BH. Interventions for preventing falls in older people living in the community. Cochrane Database Syst Rev. 2009;2:CD007146. [PMID: 19370674$]$

14. Hayes WC, Myers ER, Robinovitch SN, Van Den Kroonenberg A, Courtney AC, McMahon TA. Etiology and prevention of age-related hip fractures. Bone. 1996; 18(1 Suppl): 77S-86S. [PMID: 8717551] DOI:10.1016/8756-3282(95)00383-5
15. Lord SR. Visual risk factors for falls in older people. Age Ageing. 2006;35(Suppl 2):ii42-ii45. [PMID: 16926203] DOI:10.1093/ageing/afl085

16. Magaziner J, Simonsick EM, Kashner TM, Hebel JR, Kenzora JE. Predictors of functional recovery one year following hospital discharge for hip fracture: A prospective study. J Gerontol. 1990;45(3):M101-7. [PMID: 2335719]

17. McClure R, Turner C, Peel N, Spinks A, Eakin E, Hughes K. Population-based interventions for the prevention of fallrelated injuries in older people. Cochrane Database Syst Rev. 2005;1:CD004441. [PMID: 15674948]

18. Rose S, Maffulli N. Hip fractures: An epidemiological review. Bull Hosp Jt Dis. 1999;58(4):197-201.

[PMID: 10711369$]$

19. Owsley C, Sekuler R, Siemsen D. Contrast sensitivity throughout adulthood. Vision Res. 1983;23(7):689-99.

[PMID: 6613011]

DOI:10.1016/0042-6989(83)90210-9

20. Bennett PJ, Sekuler R, Sekuler AB. The effects of aging on motion detection and direction identification. Vision Res. 2007;47(6):799-809. [PMID: 17289106]

DOI:10.1016/j.visres.2007.01.001

21. Stevens JC, Cruz LA, Marks LE, Lakatos S. A multimodal assessment of sensory thresholds in aging. J Gerontol B Psychol Sci. 1998;53(4):P263-72. [PMID: 9679518]

22. Fitzgibbons PJ, Gordon-Salant S. Aging and temporal discrimination in auditory sequences. J Acoust Soc Am. 2001; 109(6):2955-63. [PMID: 11425137]

DOI:10.1121/1.1371760

23. Mojet J, Christ-Hazelhof E, Heidema J. Taste perception with age: Generic or specific losses in threshold sensitivity to the five basic tastes? Chem Senses. 2001;26(7):845-60. [PMID: 11555480] DOI:10.1093/chemse/26.7.845

24. Stevens JC, Dadarwala AD. Variability of olfactory threshold and its role in assessment of aging. Percept Psychophys. 1993;54(3):296-302. [PMID: 8414888]

25. Pai YC, Rymer WZ, Chang RW, Sharma L. Effect of age and osteoarthritis on knee proprioception. Arthritis Rheum. 1997;40(12):2260-65. [PMID: 9416866] DOI:10.1002/art.1780401223

26. Skinner HB, Barrack RL, Cook SD. Age-related decline in proprioception. Clin Orthop Relat Res. 1984;184:208-11. [PMID: 6705349]

27. Stevens JC, Foulke E, Patterson MQ. Tactile acuity, aging, and braille reading in long-term blindness. J Exp Psychol Appl. 1996;2(2):91-106. DOI:10.1037/1076-898X.2.2.91

28. Gescheider GA, Edwards RR, Lackner EA, Bolanowski SJ, Verrillo RT. The effects of aging on information-processing channels in the sense of touch: III. Differential sensitivity to changes in stimulus intensity. Somatosens Mot Res. 1996;13(1):73-80. [PMID: 8725651$]$ DOI:10.3109/08990229609028914 
29. Wolfson L. Gait and balance dysfunction: A model of the interaction of age and disease. Neuroscientist. 2001;7(2): 178-83. [PMID: 11496928] DOI:10.1177/107385840100700212

30. Baloh RW, Fife TD, Zwerling L, Socotch T, Jacobson K, Bell T, Beykirch K. Comparison of static and dynamic posturography in young and older normal people. J Am Geriatr Soc. 1994;42(4):405-12.

31. Miyata H, Shirato H. Gait of the elderly. Equilib Res. 1994; 53:449-57.

32. Turvey MT, Carello C. Some dynamic themes in perception and action. In: Port RF, Van Gelder T, editors. Mind as motion: Explorations in the dynamics of cognition. Cambridge (MA): MIT Press; 1995. p. 373-401.

33. Kim DS, Wall Emerson RW, Curtis A. Drop-off detection with the long cane: Effects of different cane techniques on performance. J Vis Impair Blind. 2009;103:519-30.

34. De Schonen S, Mancini J, Camps R, Maes E, Laurent A. Early brain lesions and face-processing development. Dev Psychobiol. 2005;46(3):184-208. [PMID: 15772971] DOI:10.1002/dev.20054

35. Sathian K. Visual cortical activity during tactile perception in the sighted and visually deprived. Dev Psychobiol. 2005; 46(3):279-86. [PMID: 15772968] DOI:10.1002/dev.20056

36. Birch EE, Hale LA. Operant assessment of stereoacuity. Clin Vis Sci. 1989;4:295-300.

37. Sharma A, Dorman MF, Spahr AJ. A sensitive period for the development of the central auditory system in children with cochlear implants: Implications for age of implantation. Ear Hearing. 2002;23(6):532-39. [PMID: 12476090$]$ DOI:10.1097/00003446-200212000-00004

38. Drever J. Early learning and the perception of space. Am J Psychol. 1955;68(4):605-14. [PMID: 13275606] DOI:10.2307/1418788

39. Facchini S, Aglioti SM. Short term light deprivation increases tactile spatial acuity in humans. Neurology. 2003; 60(12):1998-99. [PMID: 12821752]

40. Ferrell WR, Crighton A, Sturrock RD. Age-dependent changes in position sense in human proximal interphalangeal joints. NeuroReport. 1992;3:259-61. [PMID: 1515581] DOI:10.1097/00001756-199203000-00011

41. Bullock-Saxton JE, Wong WJ, Hogan N. The influence of age on weight-bearing joint reposition sense of the knee.
Exp Brain Res. 2001;136(3):400-406. [PMID: 11243482] DOI:10.1007/s002210000595

42. Kaplan FS, Nixon JE, Reitz M, Rindfleish L, Tucker J. Agerelated changes in proprioception and sensation of joint position. Acta Orthop Scand. 1985;56(1):72-74. [PMID: 3984706$]$

43. Petrella RJ, Lattanzio PJ, Nelson MG. Effect of age and activity on knee joint proprioception. Am J Phys Med Rehabil. 1997;76(3):235-41. [PMID: 9207711] DOI:10.1097/00002060-199705000-00015

44. Perry SD. Evaluation of age-related plantar-surface insensitivity and onset age of advanced insensitivity in older adults using vibratory and touch sensation tests. Neurosci Lett. 2006;392(1-2):62-67. [PMID: 16183200] DOI:10.1016/j.neulet.2005.08.060

45. Wells C, Ward LM, Chua R, Inglis JT. Regional variation and changes with ageing in vibrotactile sensitivity in the human footsole. J Gerontol A-Biol. 2003;58(8):680-86. [PMID: 12902525]

46. LaGrow SJ, Weessies M. Orientation and mobility: Techniques for independence. Palmerston North (New Zealand): The Dunmore Press; 1994.

47. Gescheider GA. Psychophysics: The fundamentals. 3rd ed. Mahwah (NJ): L. Erlbaum Associates; 1997. p. 45-48.

48. Welch B. On the comparison of several mean values: An alternative approach. Biometrika. 1951;38(3-4):330-36.

49. Cohen J. Statistical power analysis for the behavioral sciences. 2nd ed. Mahwah (NJ): L. Erlbaum Associates; 1988. p. 273-311.

50. Erdfelder E, Faul F, Buchner A. GPOWER: A general power analysis program. Behav Res Meth Instr. 1996;28(1): $1-11$.

51. Keppel G. Design and analysis: A researcher's handbook. 3rd ed. Englewood Cliffs (NJ): Prentice Hall; 1991.

52. Liu JX, Eriksson PO, Thornell LE, Pedrosa-Domellöf F. Fiber content and myosin heavy chain composition of muscle spindles in aged human biceps brachii. J Histochem Cytochem. 2005;53(4):445-54. [PMID: 15805419] DOI:10.1369/jhc.4A6257.2005

53. Patla AE, Frank JS, Winter DA, Rietdyk S, Prentice S, Prasad S. Age-related changes in balance control system: Initiation of stepping. Clin Biomech. 1993;8(4):179-84. DOI:10.1016/0268-0033(93)90012-7

Submitted for publication October 29, 2009. Accepted in revised form January 25, 2010. 